\title{
Multi-Drug Resistant Tuberculosis (MDR-TB)
}

(Source: Guidlines for Managing Multi Drug Resistant Tuberculossis adapted from WHO \& IUATLD documents \& guidlines)

\section{Dr. Mineab Sebhatu NTCP/MOH-Eritrea}

Tuberculosis (TB) continues to be a major cause of morbidity and mortality in Eritrea. This is all the more regrettable since the disease can be diagnosed following standard procedures and can be cured even in the presence of human immunodeficiency virus infection (HIV).

To achieve the control of TB, a standardized antituberculosis campaign must be waged throughout the country. Eritrea needs a well organized National Tuberculosis Control Programme (NTCP), operating within the existing health services with maximum involvement from the community. The NTCP will work in line with the National Health Goals and objectives which have been also articulated in the NTCP strategic plan.

Eritrea has a long history of putting its effort to control TB. The country's NTCP which is now based on the DOTS Strategy has been successfully launched all over the country and today $100 \%$ of the country is covered by DOTS. Encouraged with the success, which in the process, was instrumental in establishing the network of diagnostics and building capacity of health functionaries at all levels to manage TB, the State of Eritrea, has now taken up the daunting task of controlling one of the most dread disease, MDR-TB.

When the first line drugs were discovered over the 1940's and 1960's it was considered to be the greatest discoveries of mankind and it was considered for the first time in centuries that TB could now be eradicated and civilization freed of the menace. But unfortunately since then there have been an extensive "misuse" of these wonder drugs which have now resulted in a new public health nightmare, the drug-resistant TB, a form of TB that is much more difficult and costly to treat. But let alone, this in itself can create havoc and reverse all the gains made so far in the health status of the population.

WHO estimate nearly half million new cases of MDRTB, about $5 \%$ of the total nine million new TB cases - appear worldwide each year, as a result of under investments for TB control, poor management of antiTB drugs and transmission of drug-resistant strains.

For the African region WHO estimates $2 \%$ prevalence as a whole, however there can be much regional variations.

In Eritrea, with the present data available for the past several years, the failure rate among the pre-treatment cases is $8 \%$ (2008). The relapse cases have increased from $2 \%$ in 2003 to $3.3 \%$ in 2007 and 2008 . The relapse and failure cases rate together have increased from $2.4 \%$ in 2003 to $3.7 \%$ and $4.1 \%$ in the years 2007 and 2008 respectively. This indicates that there could be a possible emergence of drug resistance TB in Eritrea. Although these cases represent a small minority of the overall caseload of TB patients in Eritrea, they constitute an on-going problem for the programme,

both from epidemiological and human rights point of view. Also, they are small in relation to percentages and proportions, these rates may translate into sufficient absolute number of people for the condition to be taken seriously as a public health problem with a potential of becoming a major issue. MDR-TB patients often live a number of years before succumbing to the disease. Therefore MDR-TB prevalence may be several times greater than its incidence. This therefore calls for concerted effort to handle this serious problem.

\section{WHO estimates in its MDR, XDR-TB report mentioned that 490,000 MDR-TB cases emerge every year, with more than 110,000 deaths. This figure is in contrast to the 19605, when rifampicin was introduced and not a single case had yet been documented.}

Appropriate care of these MDR-TB patients would cost more than the care of all drug-susceptible

Recognizing the importance and the need to control drug resistant TB, NTCP, with its well established network in the whole country, has taken up the task to address the needs of this group of patients.

\section{Emergence of drug resistance}

When a single drug is used to treat a large bacillary load of TB organisms, the susceptible organisms are killed and gradually, the resistant strains multiply and constitute a greater percentage of the population. Subsequently, the patient experiences clinical, microbiologic and treatment failure. Therefore multidrug regimens have to use to have multiple mechanism of acting on the mycobacterium. This way the natural selection of the resistant strains becomes less likely. Multi drug regimens therefore soon became the hallmark of TB treatment. A multi drug regimen forms the basis of the DOTS therapy.

Mutation either spontaneous or triggered by exposure to external elements continuously occurs in nature. Mutations that confer the resistance to anti-tuberculosis drugs occur spontaneously and independently. Wild-type TB strains are those that have not previously been exposed to anti-TB drugs and have very little chance to be resistance to the first line drugs. These were the dominant strain before the era of anti-TB drugs. Although even within wildtype M. tuberculosis population's small populations of mutants are found to be resistant to anti-tuberculosis drugs, such occurrence to become clinically evidence is very remote. Known mutations account for most resistance of strains of $M$. tuberculosis to INH, R, Z, S, $E$ and fluoroquinolones. However some strains are drug-resistant and do not have any of the known mutations. Therefore the more the exposure to low or 
inappropriate dosage of anti-TB drugs the more is the chance of mutation and more the opportunity of the mutant strains getting naturally selected.

\section{Factors for development of MDR-TB}

Emergence of drug resistance can be due to microbial, clinical, and programmatic causes. But what ever the cause is the prime contributing factor is an inadequate or poorly administered treatment regimen allowing drug-resistant mutants to become the dominant strain in a patient infected with TB.

\begin{tabular}{|l|l|l|}
\hline Programmatic & $\begin{array}{l}\text { Drugs: Inadequate } \\
\text { Supply/Quantity }\end{array}$ & $\begin{array}{l}\text { Patients: Inade } \\
\text { quate drug intake }\end{array}$ \\
\hline $\begin{array}{l}\text { Absence of } \\
\text { guidance or }\end{array}$ & $\begin{array}{l}\text { Non-availability of } \\
\text { certain drugs (stock- } \\
\text { outs or delivery } \\
\text { disruptions) }\end{array}$ & $\begin{array}{l}\text { Poor adherence (or } \\
\text { poor DOT) - lack of } \\
\text { information }\end{array}$ \\
$\begin{array}{l}\text { guidelines } \\
\text { Non-compliance with } \\
\text { guidelines }\end{array}$ & $\begin{array}{l}\text { Poor quality } \\
\text { Poor storage } \\
\text { conditions }\end{array}$ & $\begin{array}{l}\text { non-availability of } \\
\text { free drugs }\end{array}$ \\
$\begin{array}{l}\text { Inadequate training } \\
\text { of health staff }\end{array}$ & $\begin{array}{l}\text { Wrong dosages or } \\
\text { combination }\end{array}$ \\
$\begin{array}{l}\text { No monitoring of } \\
\text { treatment }\end{array}$ & $\begin{array}{l}\text { Social and } \\
\text { economic barriers }\end{array}$ \\
$\begin{array}{l}\text { Poorly organized or } \\
\text { funded TB control } \\
\text { programmes }\end{array}$ & & Malabsorption \\
\hline
\end{tabular}

MDR-TB is man made phenomenon - poor treatment, poor drugs adherence lead to the development of MDR-TB.

Use of standardized short course chemotherapy in patients diseased with multi-drug resistant TB strains fails to cure a significant proportion of such cases and can create even more implies to the drugs in use. This has been termed the "amplifier effect of short course therapy" and it implies that the resistant strains in the bacterial population are selected repeatedly when a regimen is used continuously over a long period in a given community and these become the dominant strains.

\section{Patterns of resistance}

Drug resistance in a new TB case: Presence of resistant strain of $M$. tuberculosis in a newly diagnosed TB patient who has not previously been treated with TB drugs (or therapy of less than 1 month duration). These patients were likely to have been infected with a strain that was already drug-resistant. These cases are sometimes referred to as "primary drug resistance".

Drug resistance in a previously treated TB case: Presence of a resistant strain in a TB patient who has previously received at least 1 month of TB therapy. These cases are likely to have been initially infected with a drug - susceptible M. tuberculosis strain, but during the course of anti-tuberculosis treatment, drug resistance emerged (sometimes referred to as "secondary drug resistance").

Without molecular fingerprinting of original and subsequent isolates, it is impossible to discern whether previously treated patients have always been infected with drug-resistant strains, were re-infected with a new drug-resistant strain (primary resistance, or whether their strains evolved on treatment (secondary resistance). Therefore the current terminology, 'drug resistance in new TB cases' and 'drug resistance in previously treated TB cases' is being used.

\section{Definitions:}

As per the sensitivity pattern can be different patterns of drug resistance. For the case management and implementation of DOTS Plus program the following WHO definitions will be used to label patient with different pattern of resistance for further management.

Confirmed mono-resistance: Tuberculosis in patients whose infecting isolates of $M$. tuberculosis are confirmed to be resistant in vitro to one first-line anti-tuberculosis drug.

Confirmed poly-resistance: Tuberculosis in patients whose infecting isolates is resistant in vitro to more than one first-line anti-tuberculosis drugs, other than both $\mathrm{H}$ and $\mathrm{R}$.

- Confirmed MDR: Tuberculosis in patients whose infecting isolates is resistant in vitro to at least $\mathrm{H}$ and $\mathrm{R}$.

$\mathrm{XDR}-\mathrm{TB}: \mathrm{TB}$ is defined as resistance to at least $\mathrm{R}$ and INH (which is the definition of MDR-TB), in addition to any fluoroquinolone, and to at least one of the three injectable drugs used in anti-TB treatment Capreomycin, Kanamycin and Amikacin.

\section{MDR Case Finding}

In the present context, Eritrea with its established Culture and Sensitivity Testing (C\&S) facility can conduct the DST for the suspects. The program will follow the following definition to identify a MDR-TB prime suspect to be subjected to $C \& S$.

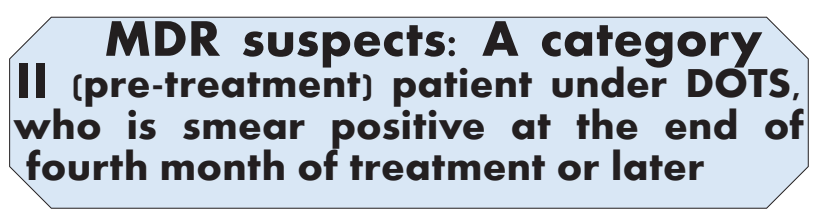

- Patients, with epilepsy, alcoholism, renal and hepatic diseases and such other medical conditions, will be included as an MDR-TB suspect. If such a patient is confirmed to have MDR-TB, it will then depend on the hospital committee to decide whether to treat the patient with CAT-IV drugs or not.

- Patients who have had more than one month of treatment with second line drugs will be included as an MDR-TB suspect and subjected to C\&S with a special request for testing of the second line drugs such as the Fluoroquinolones, especially Ofloxacilin and injectables especially Kanamycin. If such a patient is confirmed to have MDR-TB, it will then depend on the hospital treatment committee to decide upon the regimen change from the standard recommended.

In addition to those who are 'suspects' as per the definition there are other patients who should be taken as high risk for MDR. Such 'high risk' individuals should be very closely monitored by the DOT team and if strongly suggestive as $C \& S$ can be requested. The list of such individuals is mentioned below. 


\section{High risk Individuals:}

\begin{tabular}{|c|c|}
\hline Those With A History of TB & $\begin{array}{l}\text { Those Without Prior History } \\
\text { of TB }\end{array}$ \\
\hline $\begin{array}{l}\Rightarrow \text { Large bacillary load with } \\
\text { extensive (bilateral or cavitary) } \\
\text { disease } \\
\Rightarrow \quad \text { Lack of conversion of } \\
\text { cultures to negative during } \\
\text { therapy } \\
\Rightarrow \quad \text { Lack of improvement or } \\
\text { partial improvement in TB } \\
\text { symptoms } \\
\Rightarrow \quad \text { Worsening of TB symp } \\
\text { toms or radiograph findings } \\
\Rightarrow \text { Non-adherence or inte } \\
\text { rmit tent or erraptic ingestion } \\
\text { of prescribed anti-TB regimen } \\
\Rightarrow \quad \text { Lack of directly observed } \\
\text { therapy or poorly supervised } \\
\text { therapy } \\
\Rightarrow \quad \text { History of an inappropriate } \\
\text { treatment regimen, including } \\
\diamond \quad \text { Administration of } \\
\text { single drug therapy } \\
\diamond \quad \text { Too few effective } \\
\text { drugs } \\
\qquad \quad \text { Inadequate drug } \\
\text { doses } \\
H I V \text { in some settings }\end{array}$ & $\begin{array}{l}\Rightarrow \text { Exposure to a person with } \\
\text { documented drug-resistant TB } \\
\Rightarrow \text { Resistance in or travel to a } \\
\text { region with high rates of drug- } \\
\text { resistant TB } \\
\Rightarrow \text { Residence or work in } \\
\text { an institution or setting in } \\
\text { which drug-resistant TB is } \\
\text { documented } \\
\Rightarrow \text { Treatment of pulmonary } \\
\text { problems with a prolonged } \\
\text { course of multiple medicines } \\
\text { or an injectable agent for more } \\
\text { than a few weeksi.e., the patient } \\
\text { may not realize that he/she was } \\
\text { treated for TB } \\
\Rightarrow \text { HIV in some settings }\end{array}$ \\
\hline
\end{tabular}

\section{Case Finding Strategy}

The basic case finding strategy in DOTS Plus will be:

\section{Sputum Microscopy}

2. Culture and Drug Sensitivity Testing

Sputum microscopy will follow the similar pattern as that for the DOTS program i.e., collection of spotmorning-spot specimen of sputum and subjecting it to AFB microscopy. The reporting will be done as per the recommended guideline in under DOTS program.

For culture and sensitivity two samples will be collected and subjected to C\&S.

\section{Patient Management:}

A MDR-TB suspect confirmed by NHL to have MDR-TB requires treatment with Category IV regimen containing second-line anti-TB drugs.

\section{Deciding drug, regimen, dosages and duration}

\section{Classes of anti-TB drugs}

The classes of anti-TB drugs have traditionally been divided into first - and second-line drugs with isoniazid, rifampicin, pyrizinamide, ethambutol, and streptomycin being the first-line drugs. These drugs can also be grouped based on efficacy, experience of use, and drug class.

\section{Grouping Anti-TB Agents}

\begin{tabular}{|c|c|}
\hline Grouping & Drugs \\
\hline $\begin{array}{l}\text { Group 1: } \\
\text { First-line oral anti-TB agents }\end{array}$ & $\begin{array}{l}\text { Isoniazid (H); Rifampicin (R), } \\
\text { Ethambutol (E); Pyrazinamide } \\
\text { (Z) }\end{array}$ \\
\hline $\begin{array}{l}\text { Group 2: } \\
\text { Injectable anti-TB agents }\end{array}$ & $\begin{array}{l}\text { Streptomycin (S); Kanamycin } \\
(\mathrm{Km}) \text {; Amikacin (Am) } \\
\text { Capreomycin (Cm) Viomycin } \\
(\mathrm{Vm}) \text {. }\end{array}$ \\
\hline $\begin{array}{l}\text { Group 3: } \\
\text { Fluoroquinolones }\end{array}$ & $\begin{array}{l}\text { Ciprofloxacin } \quad(\mathrm{Cfx}) \\
\text { Ofloxacin (Ofx); Levofloxacin } \\
\text { (Lvx); Moxifloxacin (Mfx) } \\
\text { Gatifloxacin (Gfx) }\end{array}$ \\
\hline $\begin{array}{l}\text { Group 4: } \\
\text { Oral second line anti-TB } \\
\text { agents }\end{array}$ & $\begin{array}{l}\text { Ethionamide (Eto) } \\
\text { Prothionamide (Pto) } \\
\text { Cycloserine (Cs); Terizadone } \\
\text { (Trd); para-aminosalycilic acid } \\
\text { (PAS); Thiacetazone (T) }\end{array}$ \\
\hline $\begin{array}{l}\text { Group 5: } \\
\text { Antituberculosis agents } \\
\text { with unclear efficacy (not } \\
\text { recommended by WHO } \\
\text { for routine use in MDR-TB } \\
\text { patients) }\end{array}$ & $\begin{array}{l}\text { Clofazimine (Cfz); Amoxicillin/ } \\
\text { Clavulante (Amx/Clv) } \\
\text { Clarithromycin (Clr); linezolid } \\
\text { (Lzd). }\end{array}$ \\
\hline
\end{tabular}

\section{Creating the regimen}

Begin with any first-line agents to which the isolate is susceptible. Add a fluoroquinolone and an injectable drug based on susceptibilities (suscebtibility based on the DST survey or the DST of a representative population). While choosing the drugs keep in the mind the;

- Cost,

- Availability,

- Side effects,

- Any previous exposure to the agent

- Cross resistance and

- The experience of the physicians in using the agent.

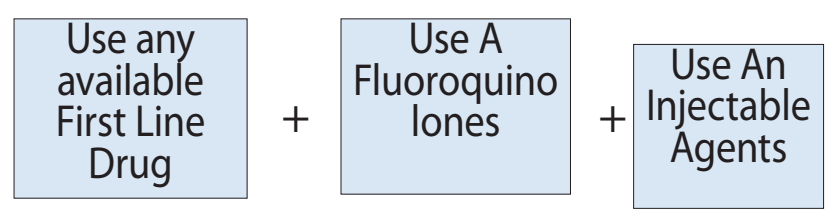

Add oral bacteriostatic, second-line drugs until you have 4-6 drugs to which the isolate is susceptible (and preferably which have not been used to treat the patient previously)

\section{Third-line drugs}

If there are no 4-6 drugs available in the above categories, consider third-line drugs in consultation with experts. 


\section{Recommended Regimen:}

The treatment regimen for the treatment of patients diagnosed as MDR can follow one of the following WHO recommended patterns:-

1. Recommended regimen

2. Standardized treatment followed by individualized treatment

3. Empirical treatment followed by individualized treatment

The regimen (Category-IV) recommended for Eritrea is:

The principles to start the new treatment in such a situations where susceptibility test results are not available are to form the regimen as perWHOguidelines till the time the DST results become available.

\section{6(9) Km Ofx Eto Cs Z / 18 Ofx Eto Cs Z}

It is recommended that the drugs should be administered in the dose related to weight band.

\section{Initiation of treatment}

Pre-treatment assessment

A very thorough assessment of a TB case is very essential if he/she is evaluated to be subjected to second-line drugs.

\section{Physical Evaluation:}

1. A thorough history of the illness

2. A thorough history of the treatment

3. Evaluation of the recent exposure to the anti-TB drugs and the duration of intake

4. Correlate the drug/s intake duration to the DST report
5. Assess the family conditions

6. History of addiction

7. History of high risk behaviour

8. A thorough physical examination and identify any other associated clinical conditions

The patient should be admitted as an in-patient when the treatment with the second-line is initiated. The duration of hospitalization depends on various factors.

It is recommended that patient should be started with a low dose (lower range) from what is applicable for the patient and gradually increased to the full dose over a period of two weeks. This will provide time for the patient to adjust to the drug intake and to the side effects thereof. This will also provide the treating physician to recognize the drug that may require change due to intolerance with any other.

\section{Patient Monitoring and Follow-up:}

Patients should be seen by the respective treating physician for clinical evaluation at least once a day in-patient during the first three to six months of the treatment. Thereafter if the patient is discharged, the patient is clinically assessed twice every month till the completion of the IP and every month during the months of $\mathrm{CP}$.

\section{Follow-up smear and culture schedule during treatment}

Four sputum specimens are to be collected and examined by smear and culture at least 30 days apart from the 3rd to 7th month of treatment and at 3 monthly intervals from the 9th month onwards till the completion of treatment. Of the four specimens, two specimens are for AFB and the other two specimens are for culture to immolate it. 